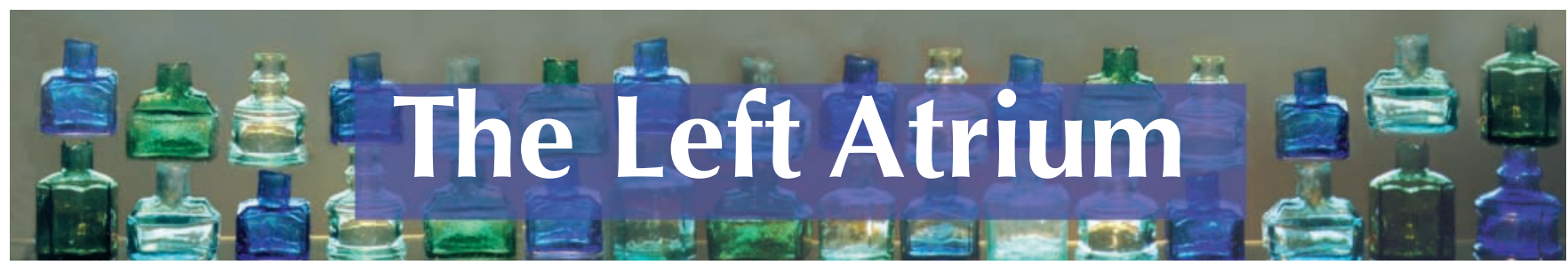

\section{The human right thing to do}

Hope in hell: inside the world of Doctors Without Borders Dan Bortolotti

Richmond Hill, ON: Firefly Books Ltd; 2004

304 pp \$35 ISBN 1-55297-865-6

Pathologies of power: health, human rights, and the new war on the poor

Paul Farmer

Berkeley, CA: University of California Press; 2004

438 pp US\$15.95 ISBN 520-24326-9

Tope in Hell: Inside the World of Doctors Without Borders is one reporter's account of the famous organization known worldwide as MSF. Built around interviews with medical and nonmedical "expats," it describes some of the contexts of MSF interventions: refugee camps, conflict zones, post-war reconstruction projects and campaigns for access to essential medications. It also describes, partly in stereotypical terms, the events leading up to the creation of MSF and its current philosophical dilemmas. The author describes MSF's genesis in a group of young doctors who wanted to relieve the world's suffering but ended up fighting among themselves according to their own cultural "traits" (the French were arrogant, the Dutch well-organized, etc). When the book focuses on the stories and motivations of individual volunteers it finds a more appropriate tone, exposing a simplistic view of "going to help and do good" and reflecting on the status of MSF volunteers in fortress houses with big SUVs, curfews and "expat" status. Bortolotti raises interesting questions on the "partnership" with local workers — is it really solidarity? He also describes horrible situations these volunteers sometimes face - such as when the MSF expats left Rwanda during the genocide and had to leave their Rwandan coworkers behind.

Some descriptions of MSF's work are paternalistic, unless the irony is well hidden. For example, in the first chapter a young Australian doctor watches as An- golan nurses try to start an intravenous line in a dehydrated child. They try and try again, for more than thirty minutes, while the doctor "stands by and calmly offers advice, refusing to take over from the nurses and undermine their training." Then one of the nurses, while moving the IV pole, "yanks the needle out of the baby's arm" and has to start the process all over again, on a baby "who by this time is as stoical as the good doctor." Unfortunately, this is almost the only passage where local staff are described in action; nowhere in the book do we see them doing things right or being helpful to the "good doctors." The book is about expats and only expats.

We are allowed a glimpse of the work "in the field," which is much more than simply doctors healing patients. In fact, the physician-patient relationship is only a small part of the story. The necessity for water and sanitation infrastructures, as well as planning for care, medication and transport is at the core of MSF's work.

Most of the book is written like a report, with the exception of the history of the movement and a few passages that try to define what a humanitarian movement should be. MSF is known for its refusal to keep quiet, its insistence on speaking out on actions that are unacceptable; the "duty to interfere" is presented as the core principle of MSF. However, the organization makes an effort to provide care to those in need, regardless of whose side they're on - hence MSF's reputa- tion for neutrality. According to Bortolotti, human rights groups focus on representation and activism, whereas humanitarian agencies tend to remain neutral to provide care to victims on all sides. The place of MSF is thus in between, one of caring for patients first without being able to keep quiet about the situations they witness. This concept of giving témoignage is present in almost every interview and vignette in this book and is required from MSF volunteers when they return from the field.

Another recently published book is such a témoignage, and a shocking one. The author, Paul Farmer, is a physician with a doctorate in anthropology who splits his time between a clinic in Haiti and a faculty position at Harvard. He is one of the founding members of Partners in Health, an organization he describes as "striving to bring the benefits of modern medical science to those most in need of them." In Pathologies of Power: Health, Human Rights, and the New War on the Poor, Farmer gives a harsh account of his experiences as well as a reflection on the causes of health disparities and inequalities. His analysis relies on the idea of "structural violence" — the violence that an intrinsically unfair system imposes on the less powerful elements within it - leading him to think that "civil rights cannot be defended if social and economic rights are not." His essay depicts various situations linked by the social inequity from which they emerge, such as tuberculosis resistant to conventional drugs in Russian prisons, communitarian health care in Chiapas during the uprising and Haiti's meagre health care system falling apart during the coups. Farmer describes the stories of individuals in unthinkable situations, relying on personal experiences and interviews in presenting an account from their own point of view. For example, he describes the story of Yolande Jean, a Haitian refugee who was detained for eleven months in an "HIV colony" in Guantanamo, in conditions that make 
one shudder, without officially being told that she had HIV, and who received an injected long-acting contraceptive without her consent or awareness. Hence Farmer exposes how the Western world is not exempt from these pathologies of power. He also describes the life of a Russian prisoner struggling with multidrug-resistant tuberculosis, whose situation was stalemated by a lack of government resources and a stubborn persistence in treating the disease with ineffective drugs.

The first half of the book tells these and other stories on health inequalities - or what Farmer, borrowing from the liberation theology, calls bearing witness. The other half of the text analyzes the foundations of the system leading to these disparities and proposes ways to change it. Farmer reflects on "marketbased medicine," on using diseases such as tuberculosis and HIV as punishment, and on the current disjunction between medical ethics and social justice. Finally, borrowing from anthropological epistemology, he calls for a paradigm shift in health and human rights.

This author also wonders why human rights are the particular domain of lawyers. Farmer strives for human rights equality through direct, communitarian actions as opposed to judicial action. $\mathrm{He}$ refuses to ask for only "basic human rights" for the poor, for they deserve equality in rights; poor people should not be treated as second-class citizens who can be guaranteed only a small part of the care and resources that Westerners have. This is another concept borrowed from liberation theology: "to care preferentially for the poor," to be on their side and to fight with them first and foremost. Like Rudolph Virchow, he sees doctors as "the natural attorneys of the poor." He considers that physicians are privileged because they can take a stand for the oppressed, and that they should do so by rejecting the costeffectiveness approach to health care and the central role of market forces.

Each of these very different books strives to "bear witness." The first is more like an oversized newspaper's special feature on a Nobel Prize-winning organization, while the other is a patchwork of reflections, theories and vivid descriptions of day-to-day health and human rights inequities. Farmer's book goes further, having a strong theoretical base for his work and submitting a working plan to change the world. If Bortolotti's book argues that doctors can't stop genocides, I get the impression that Farmer would reply that they should try ...

\section{Isabelle Leblanc}

First-year Resident

Department of Family Medicine

St. Mary's Hospital

McGill University

Montréal, Que.

\section{Lifeworks}

\section{Through the gates}

\section{The Gates}

Christo and Jeanne-Claude

Feb. 12-27, 2005

$\mathrm{T}$ he environmental artists Christo and Jeanne-Claude say there was no message, no symbolism, no purpose to The Gates, Central Park, New York City, 1979-2005, other than to be art.

"We don't define art, we create art," said Jeanne-Claude in an interview at Central Park. "Many journalists and art historians, to make their life easier, they like to have categories and labels. Christo and I believe that labels are very important - for bottles of wine."

This is a jarring admission in a cul$\infty$ ture inundated with expert information, analysis and review as we strive to order our world. This admission is all the more curious with a project like The Gates, which cost \$21 million and attracted global media attention. Surely it must mean something?

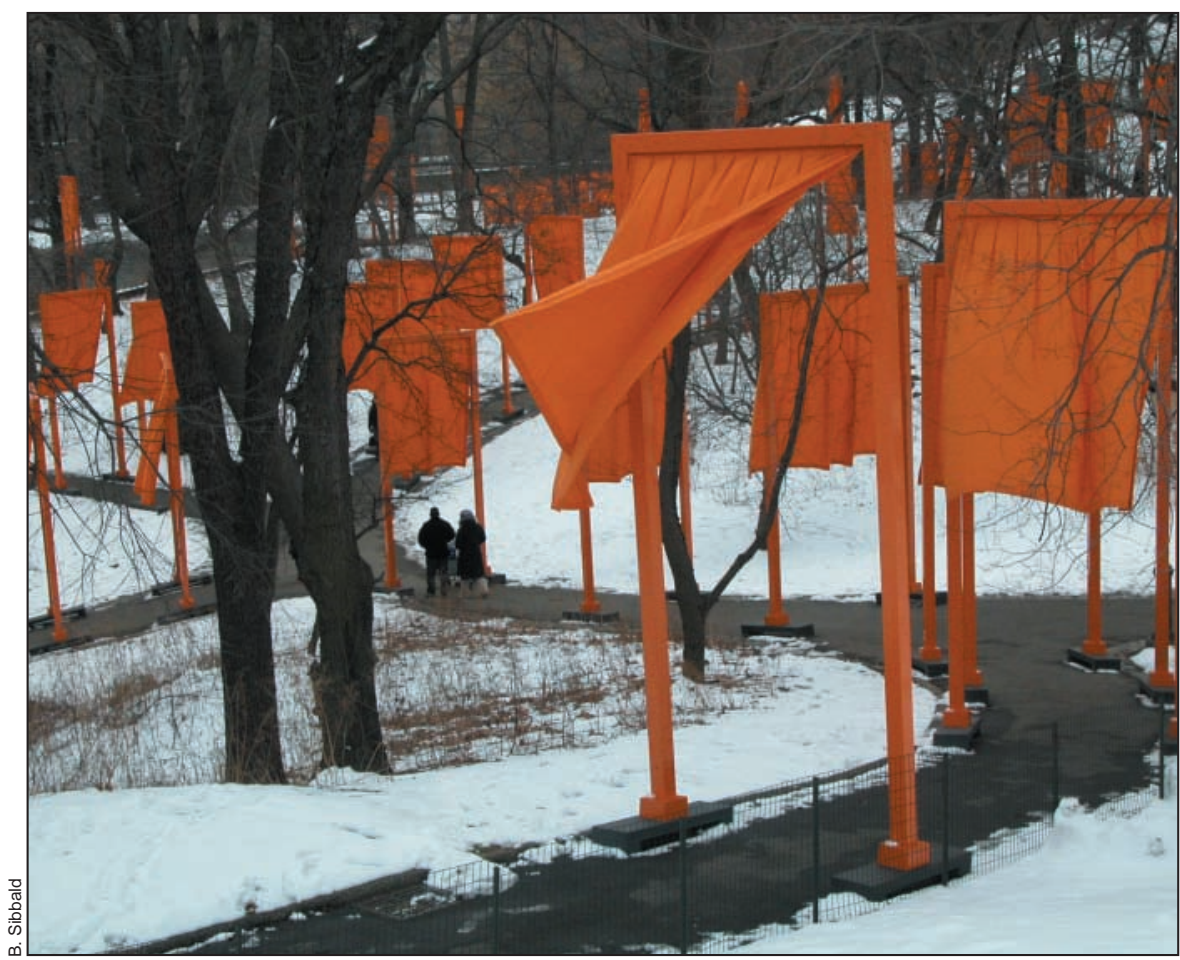

